\title{
Limits to progressive reduction of resident skin bacteria by disinfection
}

\author{
H. A. LILly, E. J. L. LOWBURY, AND M. D. WILKINS \\ From the MRC Industrial Injuries and Burns Unit, Birmingham Accident Hospital
}

SUMMARY Antiseptic preparations used repeatedly to disinfect the skin caused a reduction in yield of resident flora to a low equilibrium level beyond which further reduction did not occur. This equilibrium varied with the antiseptic preparation used. In a comparison of three preparations, the lowest equilibrium level was obtained with $95 \%$ ethyl alcohol. The further reduction in yield of skin bacteria on using alcohol after repeated disinfection with an antiseptic detergent preparation ('two-phase' disinfection) was not paralleled by a further reduction when the preparations used in the two phases were reversed, the antiseptic detergent being used after repeated disinfection with ethyl alcohol. 'Two-phase' disinfection was therefore seen to be due to further reduction in skin bacteria from the low equilibrium obtained with the antiseptic detergent to the lower level obtainable by alcohol disinfection. When repeated disinfection to equilibrium with alcohol was followed by a 'second-phase' handwash with a non-antiseptic detergent and water, there was a large increase in the yield of skin bacteria. This finding supports the view that a low equilibrium level occurs when the reduction in density of accessible bacteria through disinfection is balanced by the emergence of bacteria drawn from deeper layers of the skin.

Repeated disinfection of the skin with hexachlorophane or chlorhexidine detergent preparations at intervals over a period of two or three days has been shown to cause a progressive reduction in the yield of bacteria on sampling until a low level is reached, from which there is no further reduction when the skin is given an immediate further treatment with the same preparation (Lowbury, 1973). But if, after two or three days' repeated disinfection with hexachlorophane or chlorhexidine detergent preparations, the skin was given a further immediate disinfection with a different preparation, $0.5 \%$ chlorhexidine in $70 \%$ ethyl alcohol, a further mean reduction of $90 \%$ or more in the yield of bacteria was shown to occur (Lowbury et al., 1964; Lowbury and Lilly, 1973). Such 'two-phase' disinfection has been considered an appropriate method for achieving a higher degree of disinfection of operation sites in high-risk patients.

In the study reported here we have examined the possibility of 'two-phase' disinfection with the order of treatments reversed, the aqueous antiseptic detergent being used after repeated applications of ethyl alcohol in the manner described by Lowbury et al. (1974). We have also obtained evidence to

Received for publication 26 October 1978 show why further disinfection fails after the yield of bacteria from the skin has been reduced to a low equilibrium level, and how this level varies with different antiseptic preparations.

\section{Material and methods}

The relative effectiveness of different methods of disinfection was assessed in terms of reduction in yield of natural (predominantly resident) skin flora from the hands. Counts of samplings taken before and after disinfectant treatment were compared. The methods were those described elsewhere (Lowbury et al., 1964, 1974), which involved viable counts of bacteria in standard washings taken from the hands before and after single and repeated treatments, using Ringer's solution with appropriate neutralisers, and neutralisers in the culture media to prevent carry-over of antiseptic from skin to medium; tests for carry-over were made in selected experiments. Two groups of experiments were made:

\section{(1) 'TWO-PHASE' DISINFECTION}

Assessment was made of the reduction in yield of skin bacteria after a series of six hand disinfections with $95 \%$ ethanol (ethyl alcohol), three on one day and three on the next, the last of these followed 
immediately by $(a)$ disinfection with $95 \%$ ethanol, (b) disinfection with $0.5 \%$ chlorhexidine in $95 \%$ ethanol, (c) aisinfection with a $4 \%$ chlorhexidine detergent solution (Hibiscrub) and water, and (d) a standard 2 minutes' handwash with a nonantiseptic detergent (the base used for Hibiscrub) and water. Ethanol was used on 16 volunteers, and in the 'second phase' four volunteers were treated with each of the preparations $a, b, c$, and d.

The $95 \%$ ethanol and $0.5 \%$ chlorhexidine in ethanol preparations were made up with $1 \%$ glycerol as an emollient; two lots of $5 \mathrm{ml}$ were rubbed vigorously and systematically onto the entire surface of both hands until they were dry, as described by Lowbury et al. (1974). Hibiscrub was used, as described elsewhere (Lowbury et al., 1973), in a systematic 2 minutes' handwash with additions of warm water from a tap, followed by thorough rinsing and drying on a sterile towel; the same procedure was used in the control standard 2 minutes' handwash with a non-antiseptic detergent solution.

\section{(2) LIMITS TO PROGRESSIVE DISINFECTION}

The further reduction in estimated skin bacteria on using alcoholic chlorhexidine after repeated use of an antiseptic detergent preparation might be simply explained if the use of alcoholic chlorhexidine normally led to a lower density of skin bacteria and a lower limit of progressive 'degerming' on repeated application than that obtained with the antiseptic detergent solution; the further reduction using alcoholic chlorhexidine could then be seen as an extension from the low equilibrium level reached by repeated use of Hibiscrub to a lower level obtainable with the alcoholic solution.

The low equilibrium yield of bacteria obtained after repeated use of $95 \%$ ethanol, Hibiscrub, and $1 \%$ chlorocresol in a detergent base (Lowbury and Lilly, 1973) was determined by 12 successive hand disinfections over a period of four days; viable bacterial counts of standard handwashings were obtained after each disinfection with alcohol and with Hibiscrub, and after disinfections 1-6, 9, and 12 with chlorocresol.

After every experiment a week or more elapsed before further experiments, so that the resident flora on the hands of volunteers could be restored to their normal equilibrium levels.

\section{Results}

'TWO-PHASE' DISINFECTION

Figure 1 and the Table show that there was no further reduction in mean viable counts of bacteria, on skin sampling, from a single standard pre-

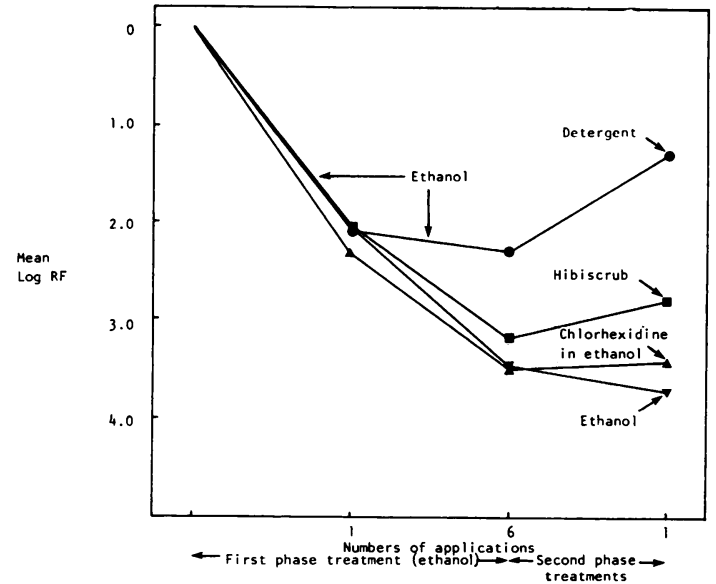

Fig. 1 Mean log reduction factors of bacteria in samplings from hands after one and six treatments with $95 \%$ ethanol, and after an immediate further treatment with (1) $95 \%$ ethanol, (2) $0.5 \%$ chlorhexidine in $95 \%$ ethanol, (3) Hibiscrub, and (4) a non-antiseptic detergent solution (the base of Hibiscrub); four volunteers were used in each group.

operative hand disinfection with a $4 \%$ chlorhexidine detergent preparation (Hibiscrub) when this was done immediately after the last of a series of treatments with $10 \mathrm{ml}$ of $95 \%$ ethyl alcohol rubbed on to the hands until they were dry. By contrast, treatment with alcoholic chlorhexidine after a series of treatments with Hibiscrub, as reported previously (Lowbury et al., 1974), caused a considerable further reduction in yield of skin bacteria; such 'two-phase' disinfection was apparent also in these experiments. Though a further treatment with Hibiscrub in the second phase of this experiment caused a mean reduction of $33.5 \%$ in the yield of skin bacteria, the mean percentage reduction after treatment with alcoholic chlorhexidine was greater $(78.6 \% ; \mathrm{P}<0.05)$.

The $\log$ reduction factor $(\log \mathrm{RF})$ (Rotter $e t$ al., 1974; Lilly et al., 1979), which was used in assessments of statistical significance (Table), is the logarithm of the viable count of pretreatment samples minus the logarithm of the viable count of post-treatment samples; a log RF of 1.00 corresponds with a $90 \%$ reduction, and a $\log \mathrm{RF}$ of 2.00 corresponds with a $99 \%$ reduction.

Figure 1 and the Table show that on washing the hands with a detergent and water after repeated disinfection to the low equilibrium level of skin bacteria with $95 \%$ alcohol, there was a sharp rise in the numbers of bacteria yielded on sampling. These bacteria must have been present in the deeper 
Table Reduction in yield of bacteria from skin on disinfection

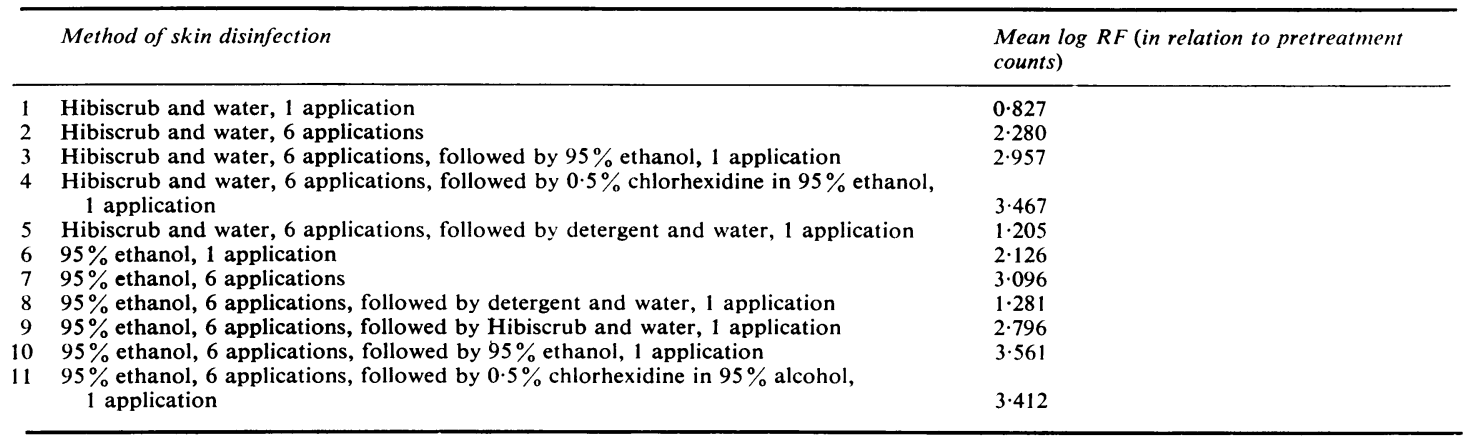

Comparison of methods

1 v. $2: t=5.30, \mathrm{P}=0.00002$

1 v. $6: t=9 \cdot 69, \mathrm{P}=4.3 \times 10^{-10}$

$6 v .7: t=5.03, \mathrm{P}=0.00002$

2 v. $7: t=2.75, \mathrm{P}=0.001$

8 v. $7: t=9 \cdot 21, \mathrm{P}=0.00009$

$$
\begin{aligned}
2 v .4: t & =2.09, \mathrm{P}=0.08 \text { (NS) } \\
7 v .10: t & =5.29, \mathrm{P}=0.62 \text { (NS) } \\
7 v .11: t & =1.37, \mathrm{P}=0.89 \text { (NS) } \\
2 \text { v. } 5: t & =9 \cdot 61, \mathrm{P}=0.37 \text { (NS) } \\
10 v .11: t & =0.41, \mathrm{P}=0.70 \text { (NS) }
\end{aligned}
$$

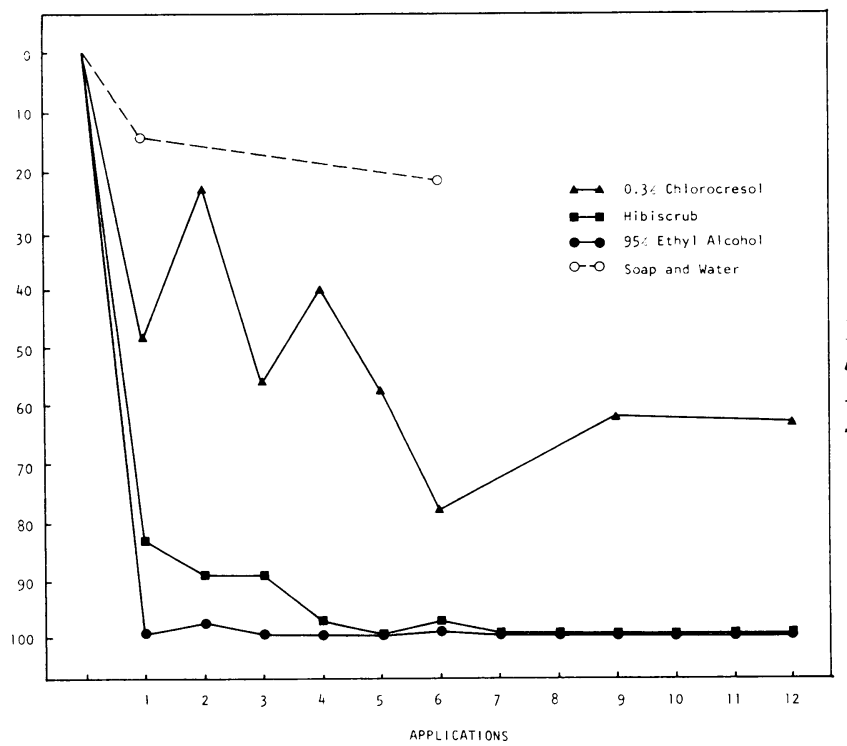

Fig. 2 Mean percentage reduction in yield of skin bacteria on repeated treatment of hands with soap, Hibiscrub, and chlorocresol ( $0.3 \%$ ) detergent solution and water, and with $95 \%$ ethanol.

layers of the skin and brought to the surface by the massaging effects of the handwash. These findings are consistent with the hypothesis that a lower limit to reduction in bacterial yields from skin on repeated disinfection with alcohol was due to the establishment of a low equilibrium level, in which the killing of organisms on the surface is offset by the emergence of living organisms from deeper layers of the skin.

LIMITS TO PROGRESSIVE DISINFECTION

Figure 2 shows the mean numbers of bacteria yielded from skin samplings before disinfection and after each of the 12 successive disinfections with three antiseptic preparations. Mean log reduction factors after each of the disinfectant treatments are plotted in Figure 3.

The three methods gave different curves of progressive reduction in yield of bacteria, the limiting density being lowest with ethanol (and possibly not reached even after 12 treatments) and highest with chlorocresol.

These findings are consistent with the hypothesis put forward above to explain 'two-phase' disinfection. 


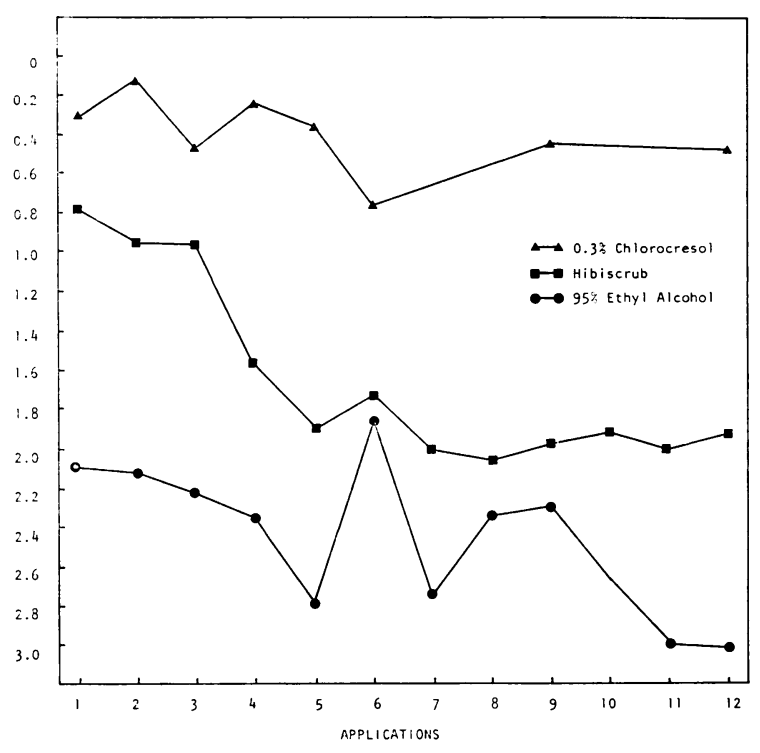

Fig. 3 Log reduction factors of yield of skin bacteria after 1-12 treatments with Hibiscrub and chlorocresol $(0.3 \%)$ detergent solution and water, and with $95 \%$ ethanol.

\section{Discussion}

The experiments described here show the mechanisms by which treatment with alcoholic chlorhexidine supplemented the effects of a series of treatments with detergent preparations of chlorhexidine or hexachlorophane after these had reached the limit of their cumulative action. This 'two-phase' disinfection is shown to be due to further reduction in skin bacteria when the skin is disinfected by a method more effective than that which was used in the first phase of disinfection; if the order was reversed, and repeated applications of alcohol were followed by hand preparation with the antiseptic detergent Hibiscrub, there was no further drop in skin bacteria in the second phase; there was a slight, though not significant, rise. The practical implications of this are that an operation site could, if this were convenient, be as effectively disinfected by a series of three or four treatments with alcoholic chlorhexidine or even with $95 \%$ (or $70 \%$ ) ethanol as by 'two-phase' disinfection with Hibiscrub followed by alcoholic chlorhexidine. Our earlier hypothesis (Lowbury and Lilly, 1973) that 'twophase' disinfection could be due to the successive action of different mechanisms of disinfection is not supported.

The fact that one cannot reduce the density of skin bacteria (as judged by the yield of bacteria on sampling) below a certain level, which varies with the antiseptic used, is on first sight surprising, but it can be explained by postulating a balance of factors, destruction of bacteria by the antiseptic, and emergence, on washing, of bacteria from deeper layers of the skin. This hypothesis is supported by the fact that washing with a detergent and water when the hands had been repeatedly disinfected caused a large increase in the numbers of bacteria yielded on sampling of the skin. This experiment emphasises how far we are from rendering the skin sterile even with the best of antiseptic methods, and how ineffective and, on very clean hands, even potentially counterproductive (against resident bacteria) is the detergent cleansing of the skin with nonantiseptic preparations such as soap and water. Against the transient flora, on the other hand, washing with soap and water has been found as effective as washing with a detergent antiseptic and water, though less effective than antiseptic with no addition of water (Lilly and Lowbury, 1978).

We thank members of our staff for acting as volunteers in this study.

\section{References}

Lilly, H. A., and Lowbury, E. J. L. (1978). Transient skin flora. Their removal by cleansing or disinfection in relation to their mode of deposition. Journal of Clinical Pathology, 31, 919-922.

Lilly, H. A., Lowbury, E. J. L., and Wilkins, M. D. (1979). Detergents compared with each other and with antiseptics as skin degerming agents. Journal of Hygiene, 82, 89-93.

Lowbury, E. J. L. (1973). Skin preparation for operation. British Journal of Hospital Medicine, 10, 627-634.

Lowbury, E. J. L., and Lilly, H. A. (1973). Use of $4 \%$ chlorhexidine detergent solution (Hibiscrub) and other methods of skin disinfection. British Medical Journal, 1, 510-515.

Lowbury, E. J. L., Lilly, H. A., and Ayliffe, G. A. J. (1974). Preoperative disinfection of surgeons' hands: use of alcoholic solutions and effects of gloves on skin flora. British Medical Journal, 4, 369-372.

Lowbury, E. J. L., Lilly, H. A., and Bull, J. P. (1964). Methods for disinfection of hands and operation sites. British Medical Journal, 2, 531-536.

Rotter, M., Mittermayer, H., and Kundi, M. (1974). Untersuchungen zum Modell der künstlich kontaminierten Hand: Vorschlag für eine Prüfmethode. Zentralblatt für Bakteriologie und Hygiene, Orig. B, 159, 560-581.

Requests for reprints to: Dr E. J. L. Lowbury, MRC Industrial Injuries and Burns Unit, Birmingham Accident Hospital, Bath Row, Birmingham B15 1NA. 